\title{
Aberrant Left Internal Iliac Artery Originating from the Aortic Bifurcation
}

\author{
Chan Yong Park, M.D.
}

Department of Trauma Surgery, Pusan National University Hospital, Busan, Korea

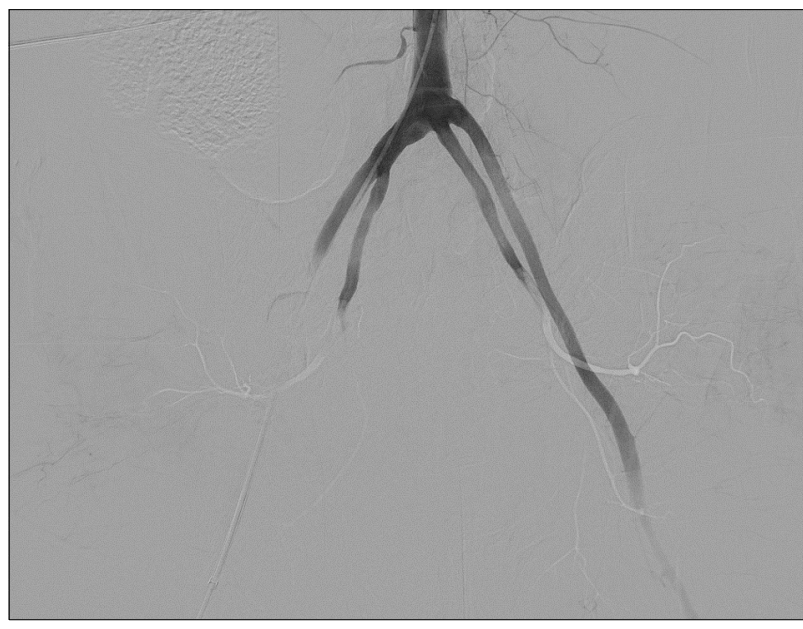

Fig. 1. In angiography, the left internal iliac artery is directly originated from the aorta.

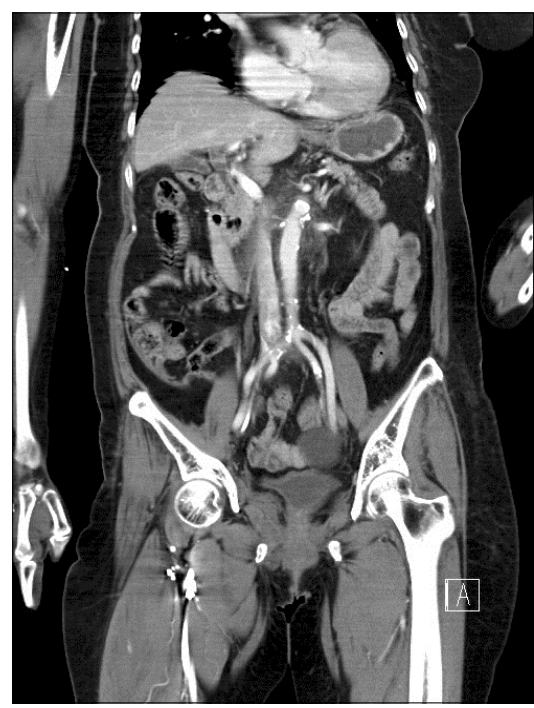

Fig. 2. The left internal iliac artery is directly branched from the aorta.
Received May 23, 2018,

Accepted August 2, 2018

Correspondence to: Chan Yong Park, M.D. Department of Trauma Surgery, Pusan National University Hospital, 179 Gudeok-ro, Seo-gu, Busan 49241, Korea Tel: +82-51-240-7369, Fax: +82-51-240-7719, E-mail: traumawkuh@gmail.com ORCID:

http://orcid.org/0000-0002-5111-3270

Chan Yong Park's current affiliation Department of Trauma Surgery, Wonkwang University Hospital, 895 Muwang-ro, Iksan 54538, Korea
The internal iliac artery mostly originates from the common iliac artery. We report a case of the aberrant left internal iliac artery directly originating from the aortic bifurcation site. A 73-year-old female presented to the emergency department via another hospital due to pelvic fracture. Emergent angiography was performed for control of the pelvic bleeding. Angiography showed both normal common iliac arteries and aberrant left internal iliac artery originating from aortic bifurcation (Fig. 1). This was also observed in computed tomography (Fig. 2). To our knowledge, this is the first report about this type of anomaly in the literature. Aberrant internal iliac artery originating from aortic bifurcation is an extremely rare vascular variation [1,2]. During the radiologic intervention for trauma patients, the possibility of various vascular abnormalities should be considered.

Copyright $(2018$ by Korean Society of Acute Care Surgery

(c) This is an Open Access article distributed under the terms of the Creative Commons Attribution Non-Commercial License (http://creativecommons.org/licenses/by-nc/4.0) which permits unrestricted non-commercial use, distribution, and reproduction in any medium, provided the original work is properly cited. 


\section{Conflicts of Interest}

No potential conflict of interest relevant to this article was reported.

\section{References}

1. Koyama T, Kawada T, Kitanaka Y, Katagiri K, Ohno M, Ikeshita M, et al. Congenital anomaly of the external iliac artery: a case report. J Vasc Surg 2003;37:683-5.

2. Hager E, Isenberg G, Gonsalves C, Moudgill N, Dong S, Dimuzio P. A new anatomic variant of the aorta: a case report. J Vasc Surg 2008;48:213-5. 